\title{
Surface latent heat flux anomalies preceding inland earthquakes in China*
}

\author{
Kai Qin ${ }^{1,2,}$ Guangmeng Guo ${ }^{2}$ and Lixin $\mathrm{Wu}^{3}$ \\ ${ }^{1}$ College of Geosciences and Surveying Engineering, China University of Mining and Technology, Beijing 100083, China \\ ${ }^{2}$ College of Environmental Science and Traveling, Nanyang Normal University, Nanyang 473061, Henan, China \\ ${ }^{3}$ Academy of Disaster Reduction and Emergency Management, Ministry of Civil Affairs, Ministry of Education
}

(Beijing Normal University), Beijing 100875, China

\begin{abstract}
Using data from the National Center for Environmental Prediction (NCEP), the paper analyzed the surface latent heat flux (SLHF) variations for five inland earthquakes occurred in some lake area, moist area and arid area of China during recent years. We used the SLHF daily and monthly data to differentiate the global and seasonal variability from the transient local anomalies. The temporal scale of the observed variations is 1-2 months before and after the earthquakes, and spatial scale is about $10^{\circ} \times 10^{\circ}$. The result suggests that the SLHFs adjacent the epicenters all are anomalous high value $(>\mu+2 \sigma) 8-30$ days before the shocks as compared with past several years of data. Different from the abnormal meteorological phenomenon, the distribution of the anomalies was isolated and local, which usually occurred in the epicenter and its adjacent area, or along the fault lines. The increase of SLHF was tightly related with the season which the earthquake occurs in; the maximal ( $125 \mathrm{~W} / \mathrm{m}^{2}$, Pu'er earthquake) and minimal $\left(25 \mathrm{~W} / \mathrm{m}^{2}\right.$, Gaize earthquake) anomalies were in summer and winter, respectively. The abundant surface water and groundwater in the epicenter and its adjacent region can provide necessary condition for the change of SLHF. To further confirm the reliability of SLHF anomaly, it is necessary to explore its physical mechanism in depth by more earthquake cases.
\end{abstract}

Key words: inland earthquake; surface latent heat flux; thermal anomaly; satellite data CLC number: P315.72 Document code: A

\section{Introduction}

Thermal anomaly phenomena before earthquake were widely studied in the world during the past decades (Qiang et al, 1999; Qiang, 2001; Tronin et al, 2002; Ouzounov and Freund 2004; Saraf and Choudhury, $2005 a, b)$. Before an earthquake event the region undergoes a long preparation period during which tectonic stress within the Earth has been developed. The accumulated energy transports between the Earth and atmosphere mainly through electromagnetic radiation, latent heat exchange, and sensible heat exchange. Ground electromagnetic radiation by outgoing longwave had been proved as an earthquake precursor (Ouzounov et al, 2007). Latent heat and sensible heat are two different kinds of effects that can be produced by heat. The

\footnotetext{
* Received 20 April 2009; accepted in revised form 20 July 2009; published 10 October 2009.

^ Corresponding author. e-mail: qinkai20071014@163.com
}

former is caused by phase changes from the surface to the air due to evaporation or from the air to the land due to condensation, and the latter by air convection or turbulence (Chen et al, 2006). Dey and Singh (2003) reported the surface latent heat flux (SLHF) anomalies before large coastal earthquake for the first time. They found that the anomalous behavior of SLHF before the main shock is only associated with the coastal earthquakes. The maximum increase of SLHF appeared 2-7 days before the main shock, and then the anomalies disappeared some days after the earthquake. Then Cervone et al (2004) further developed a wavelet analysis approach for identifying maximal peaks of SLHF associated with an impending earthquake and demonstrating the atmospheric disturbances. Afterwards, Pulinets et al (2006a) used different types of ground, atmospheric, meteorological, atmospheric and ionospheric data to study the relationship between latent heat and humidity variations around the time of the Colima M7.8 earthquake in Mexico on 21 January 2003. Chen et al (2006) 
summarized the characteristics of distribution and evolution of the SLHF before and after the Indonesia $M_{\mathrm{S}} 9.0$ earthquake in 2004. They found that the maximum anomaly before the earthquake appeared on the middle segment of the Myanmar micro-plate, where the middle part of the rupture zone was located and the aftershocks were concentrated. Recently, SLHF anomalies before some inland earthquakes are reported. Chen et al (2007) studied the variation of surface thermal flux before and after the Jiujiang M5.7 earthquake in Chinese inland area. Before the Jiujiang quake, significant SLHF anomalies appeared in the epicenter and its northern area where a lot of lakes are distributed along the active faults. Then Li et al (2008) studied the spatio-temporal features of SLHF anomaly in the epicentral regions of four earthquakes occurred in the past ten years in China, one near the coast and three far away from the coast. They revealed that abnormal SLHF all occurred 3-10 days before the earthquakes and that SLHF anomaly usually occurred in the epicenter or its surrounding area, and its spatial pattern were in accordance with the strike of local active faults.

To further study the variation of SLHF before in- land earthquakes, this paper considered five major earthquakes, with a magnitude $>6$ and a focal depth $<15$ $\mathrm{km}$, occurred in different inland regions of China, such as lake area, moist area and arid area, during recent years.

\section{Data and methodology}

The relevant parameters for five earthquakes are from USGS (Table 1). The National Center for Environmental Prediction (NCEP) provided the SLHF data, which is generated by taking into consideration the measured values at various worldwide stations including that retrieved from satellite data. The data is represented by the Gaussian grid of 94 lines from equator to pole, with a regular $1.8^{\circ}$ longitudinal spacing and projected into $2^{\circ}$ latitude by $2^{\circ}$ longitude in a rectangular grid. The fluxes used in the operational weather forecast models incorporate in-situ observations through an assimilation process. The validation and detailed description of the reanalysis of the NCEP SLHF data have been discussed by Kalnay et al (1996). The SLHF is found with accuracy of $10-30 \mathrm{~W} / \mathrm{m}^{2}$ (Smith et al, 2001).

Table 1 Details of the five earthquakes used in this study

\begin{tabular}{|c|c|c|c|c|c|c|c|c|}
\hline \multirow{2}{*}{ No. } & \multirow{2}{*}{ a-mo-d } & \multicolumn{2}{|c|}{ Epicenter } & \multirow{2}{*}{ Location } & \multirow{2}{*}{$M_{\mathrm{S}}$} & \multirow{2}{*}{$\begin{array}{l}\text { Depth } \\
\text { /km }\end{array}$} & \multirow{2}{*}{ Background noise $(\mu+2 \sigma)$} & \multirow{2}{*}{ Remark } \\
\hline & & Lat. $/{ }^{\circ} \mathrm{N}$ & Long. $/{ }^{\circ} \mathrm{E}$ & & & & & \\
\hline 1 & $2008-09-25$ & 30.8 & 83.5 & Zhongba & 6.0 & 10 & 98 (Aug.), 84 (Sept.) & Lake area \\
\hline 2 & 2008-01-09 & 32.5 & 85.2 & Gaize & 6.9 & 10 & 26 (Dec.), 44 (Jan.) & Lake area \\
\hline 3 & $2007-06-02$ & 23 & 101.1 & Pu'er & 6.4 & 6 & 254 (May), 241 (June) & Moist area \\
\hline 4 & $2003-07-21$ & 26 & 101.2 & Dayao & 6.2 & 15 & 195 (June), 199 (July) & Moist area \\
\hline 5 & $2008-03-21$ & 35.5 & 81.4 & Yutian & 7.2 & 22.9 & 119 (Feb.), 107 (March) & Arid area \\
\hline
\end{tabular}

In this paper, we investigated the daily and monthly SLHF mean values related to these major earthquakes. Firstly, we collected the daily mean values of SLHF 1-2 months before and after the earthquakes. The standard deviation of SLHF for each month has been calculated to fix the threshold values of the background noise and to differentiate the earthquake signals. This background noise may be attributed to high wind speed and atmospheric perturbations. For each earthquake, the mean value $(\mu)$ of SLHF plus 2-standard deviation $(2 \sigma)$ of SLHF shown in Table 1 has been taken as the maximum range of background noise. The SLHF values beyond the maximum range of background noise $(\mu+2 \sigma)$ are considered as anomalies. In order to remove the annual variation effect, we also compared the anomalous values with the historical long term data in the past twenty years. Then we presented the spatial distri- bution of the SLHF increment $\left(\Delta F_{\mathrm{SLH}}\right)$ over the epicenter and its adjacent areas to differentiate the global and seasonal variability from the transient local anomalies. The monthly average of ten years data has been subtracted from the daily data to minimize the monthly and seasonal effect (termed as background noise).

\section{Results}

\subsection{Zhongba $M_{S} 6.0$ earthquake on September 25, 2008}

On 25 September 2008, a $M_{\mathrm{S}} 6.0$ earthquake occurred in Zhongba country, Tibet, Southwest China. Figure 1a shows the variations of SLHF two months before and after the earthquake. On September 6, 19 days before the day of earthquake occurrence, one can see a sharp peak higher than the maximum range of the background noise. Figure 1b shows the SLHF on Sep- 
tember 6 from 1989 to 2008. In 2008 (year of the earthquake), the maximum SLHF was observed in the past twenty years. The observed SLHF was also above the maximum range of background noise considering a 20-years data set.

Figure 2 shows the spatial distribution of the SLHF values in Zhongba region before the earthquake. On September 5, the SLHF anomaly first appeared to the east of the epicenter, with $30-35 \mathrm{~W} / \mathrm{m}^{2}$ increase relative to the monthly average of ten years (1989-2008). On September 6 , the strongest $\Delta F_{\mathrm{SLH}}$ more than $40 \mathrm{~W} / \mathrm{m}^{2}$ was detected $300 \mathrm{~km}$ around the epicenter. Then, it disappeared on September 7 (Figure 2). On September 25, when the earthquake occurred, a negative increase of SLHF covered the epicenter with a value of $-30 \mathrm{~W} / \mathrm{m}^{2}$. Thereafter, the SLHF again subsided back to normal values.
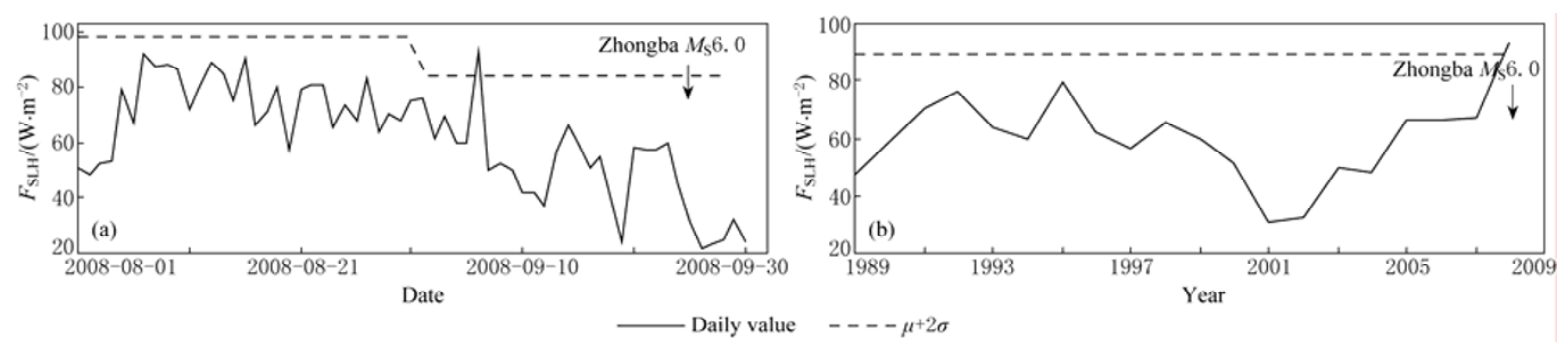

Figure 1 (a) Variations of SLHF $F_{\mathrm{SLH}}$ in the pixel $\left(31.4281^{\circ} \mathrm{N}, 82.5^{\circ} \mathrm{E}\right) 118 \mathrm{~km}$ away from the epicenter of the $M_{\mathrm{S}} 6.0$ Zhongba earthquake from August 12008 to September 30 2008; (b) The SLHF $F_{\text {SLH }}$ on September 6 in the interval of 1989-2008. Dashed lines indicate the seismic moment.
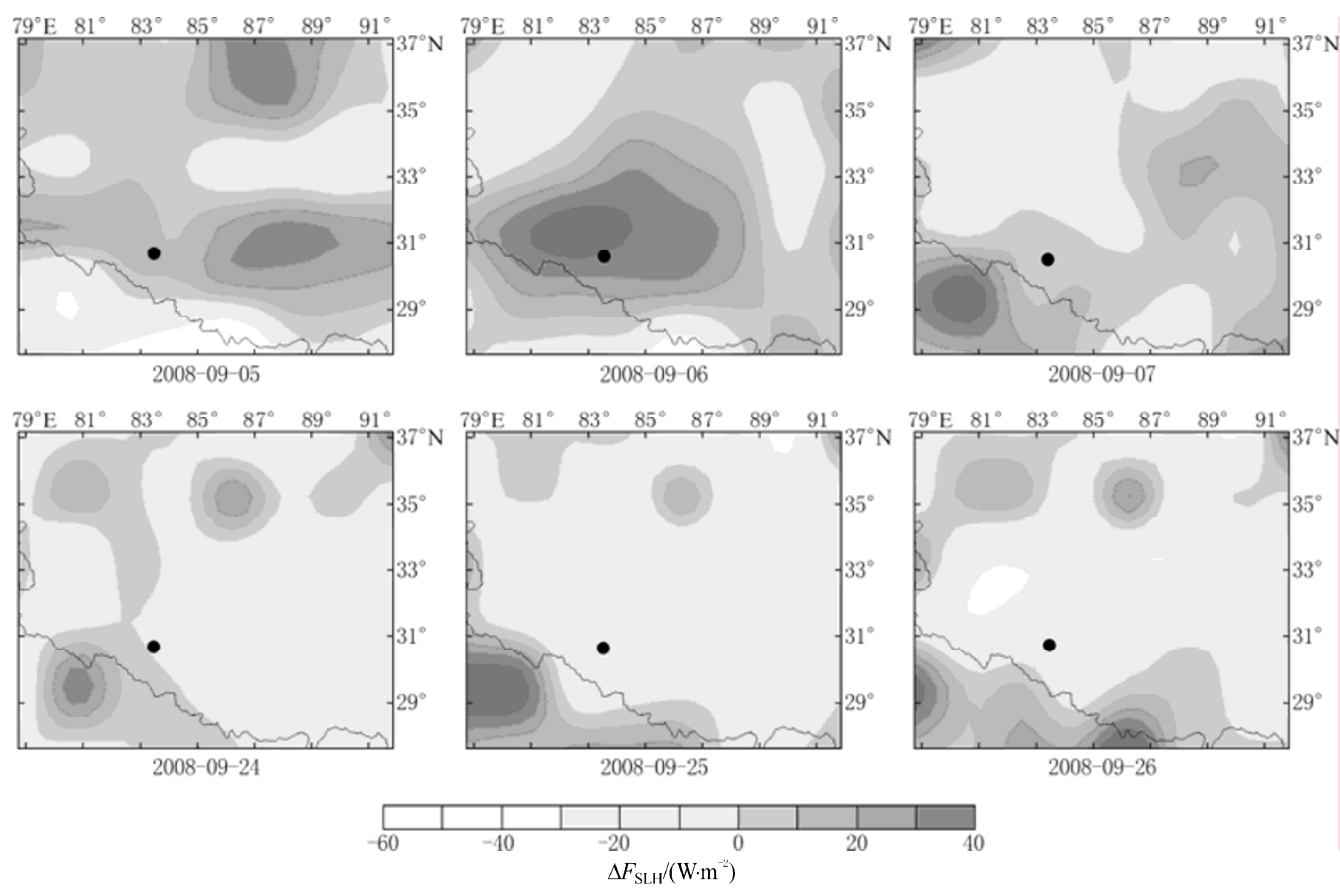

Figure 2 Spatial distribution of SLHF increment $\Delta F_{\text {SLH }}$ in Zhongba region before the $M_{\mathrm{S}} 6.0$ earthquake. Dot indicates the epicenter.

The increase of SLHF was provided by the thermal flux deposited from the Earth's crust in seismically active areas, which enhances surface water to evaporate to the air. The abundant water area adjacent the epicenter facilitates the energy to transfer to the atmosphere. There are many lakes adjacent the epicenter. The total area of the lakes within $300 \mathrm{~km}$ away from the epicenter is up to $3796 \mathrm{~km}^{2}$, which can provide abundant water source for the change of SLHF.

3.2 Gaize $M_{\mathrm{S}} 6.9$ earthquake on January 9, 2008

Similar to the Zhongba earthquake of 2008, the Gaize $M_{\mathrm{S}} 6.9$ earthquake also happened in lake area in 
2008. Although both occurred in the same tectonic settings, the different atmospheric conditions made different SLHF variation. Figure 3 a shows a singular peak of SLHF on January 1, eight days before the shock. It was earlier than the peak observed on September 6, 19 days before the Zhongba earthquake (Figure 1a). The abnormal SLHF peak was above the maximum range of background noise $(\mu+2 \sigma)$ both in the short term (Figure 3a) and long term variation of SLHF (Figure 3b). On January 1, an anomalous area was found to the south of the epicenter where a lot of lakes are distributed (Figure 4). The maximum spatial extent of this anomalous region was about $106307 \mathrm{~km}^{2}$, and the intensity of $\Delta F_{\mathrm{SLH}}$ was as high as $25 \mathrm{~W} / \mathrm{m}^{2}$. On January 3, the anomaly gradually decreased and disappeared.
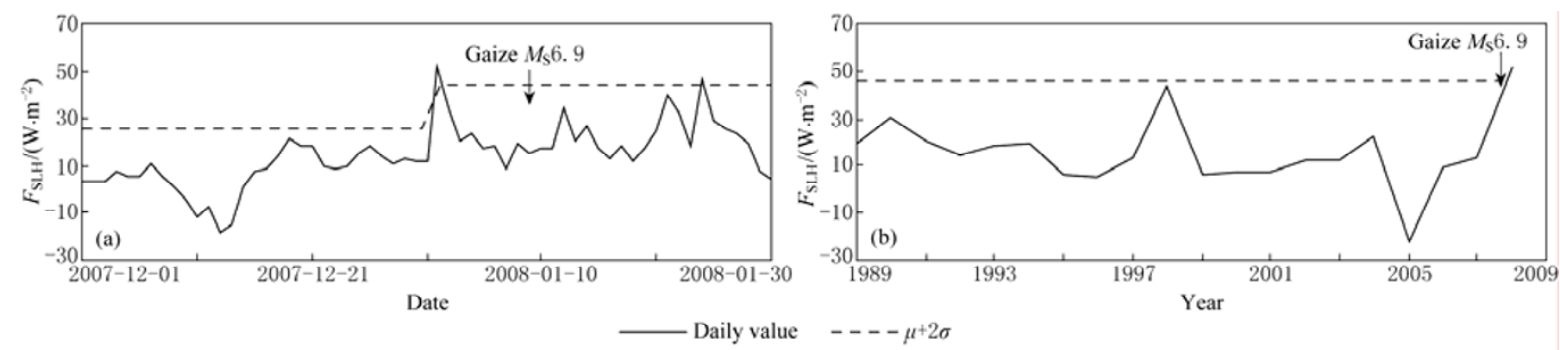

Figure 3 (a) Variations of surface latent heat flux $F_{\mathrm{SLH}}$ in the pixel $\left(31.4281^{\circ} \mathrm{N}, 84.375^{\circ} \mathrm{E}\right) 143 \mathrm{~km}$ away from the epicenter of the Gaize $M_{\mathrm{S}} 6.9$ earthquake from December 1, 2007 to January 30, 2008; (b) The SLHF $F_{\mathrm{SLH}}$ on 1 January during 1989-2008. Dashed lines indicate the seismic moment.

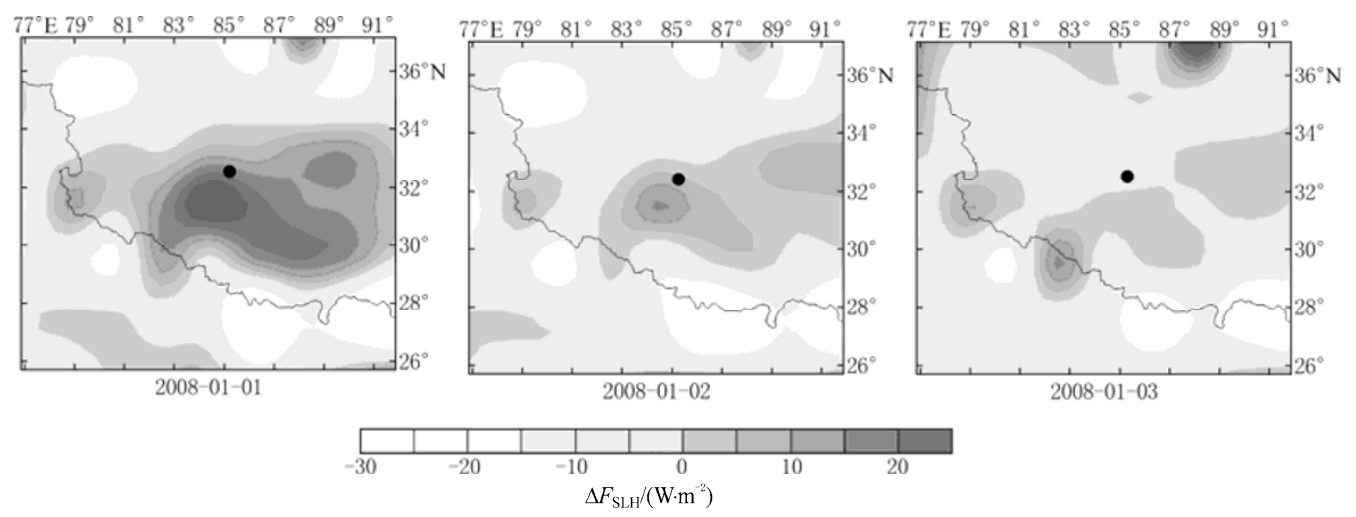

Figure 4 Spatial distribution of SLHF increment $\Delta F_{\mathrm{SLH}}$ in Gaize region before the $M_{\mathrm{S}} 6.9$ earthquake. Dot indicates the epicenter.

\subsection{Pu'er $M_{\mathrm{S}} 6.4$ earthquake on June 2, 2007}

On June 2, 2007, a destructive $M_{\mathrm{S}} 6.4$ earthquake occurred in Pu'er region $\left(23.0^{\circ} \mathrm{N}, 101.1^{\circ} \mathrm{E}\right)$, Yunnan province, Southwest China. Unlike the above two quakes occurred in Tibet with many lakes, the epicenter is located in a tropical rain forest area. The higher moisture content in the soil and humidity in the air are beneficial to the change in SLHF. The SLHF data of the pixel near the epicenter were also analyzed for two months. The data completely support the previous results (Figure 5). One can see again the largest value $(>2 \sigma)$ on May 23 , ten days before the shock. But another peak $(>1.5 \sigma)$ appeared on May 26, seven days before the shocking. On May 23, the largest SLHF increment (125 $\mathrm{W} / \mathrm{m}^{2}$ ) was found adjacent the epicenter. It was followed by a temporary fall of SLHF to again pick up a rise on May 26 (Figure 6). The difference between the two anomalies was about $20-40 \mathrm{~W} / \mathrm{m}^{2}$. Saraf et al (2008) found a dual peak in the surface temperature conditions during the Kerman earthquake. He considered a possibility of sporadic release of accumulated energy in the stressed rocks, which might lead to the reduction of the magnitude of the main shock. The two discontinuous peaks of SLHF in this case maybe have the similar cause.

\subsection{Dayao $M_{\mathrm{S}} 6.2$ earthquake on July 21,2003}

The Dayao $M_{\mathrm{S}} 6.2$ earthquake on July 21, 2003 also occurred in Yunnan province, a moist area, which is at the same longitude as the Pu'er earthquake, but with three degree latitude difference to the north. There were 


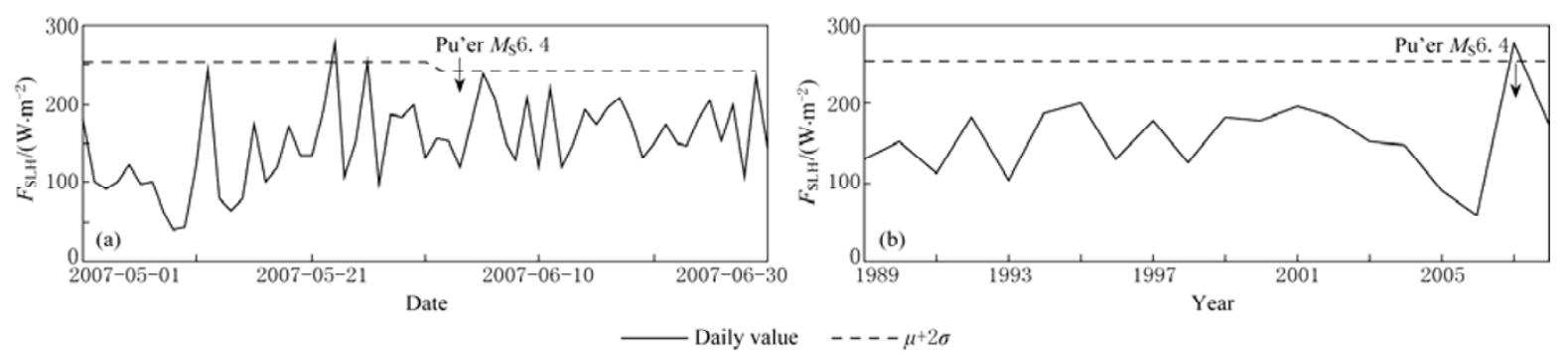

Figure 5 (a) Variations of SLHF $F_{\mathrm{SLH}}$ in the pixel $\left(23.8092^{\circ} \mathrm{N}, 101.25^{\circ} \mathrm{E}\right) 94 \mathrm{~km}$ away from the epicenter of the Pu'er $M_{\mathrm{S}} 6.4$ earthquake from May 12007 to June 30 2007; (b) SLHF $F_{\text {SLH }}$ on 23 May during 1989-2008. Dashed lines indicate the seismic moment.
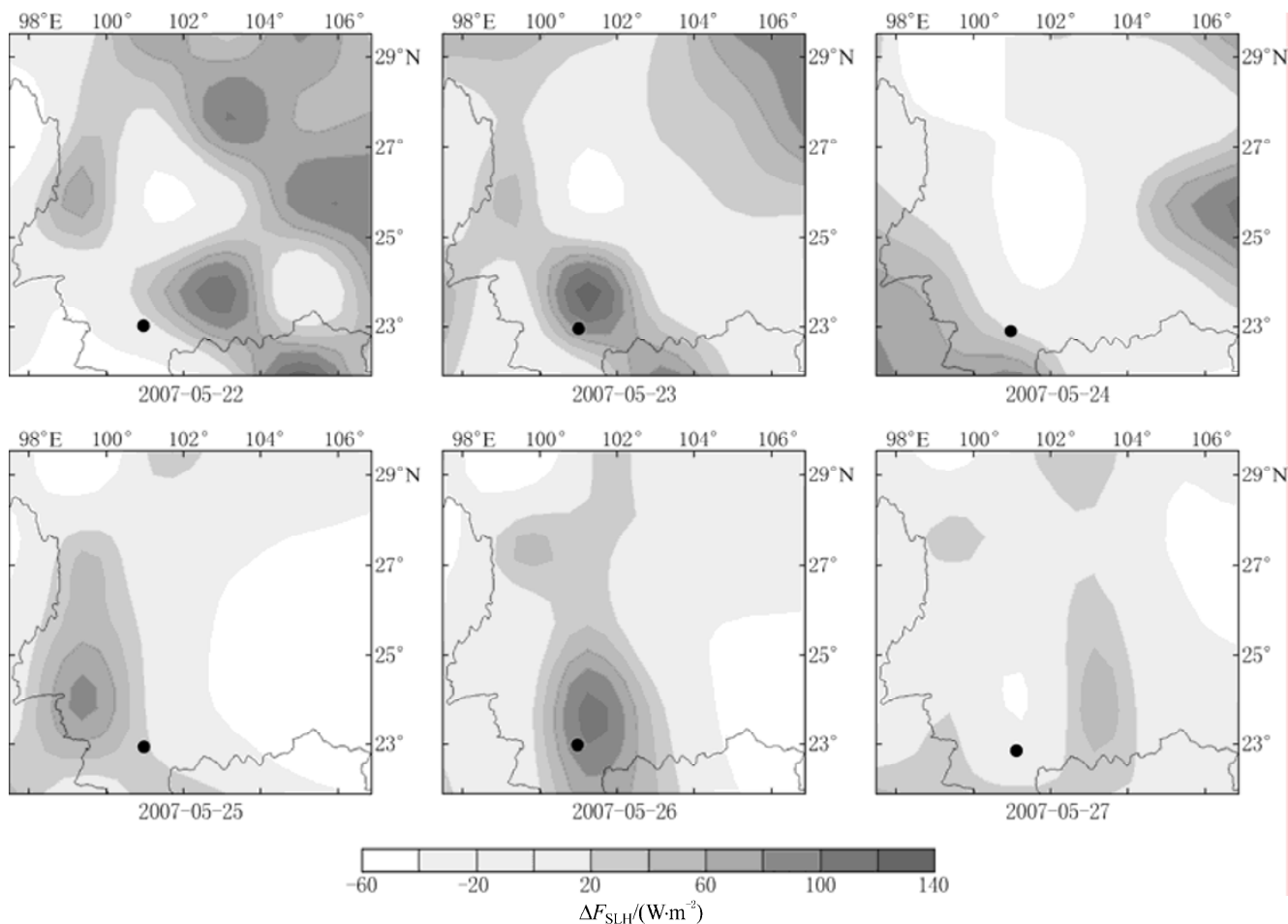

Figure 6 Spatial distribution of SLHF increment $\Delta F_{\mathrm{SLH}}$ in Pu'er region before the $M_{\mathrm{S}} 6.4$ earthquake. Dot indicates the epicenter.

two continuous peaks in the time-series of SLHF near the epicenter both higher than the background noise $(\mu+2 \sigma)$, on July 9 and 10 , respectively (Figure 7). On 11 July 2003, the SLHF started to drop gradually, and near the falling edge the earthquake occurred. Figure 8 reveals that the anomaly is also of local characteristic. The observed SLHF increases eleven days and twelve days before the shock are up to $60-70 \mathrm{~W} / \mathrm{m}^{2}$, with a large patch of intense anomalous region covering the epicenter. On July 21, 2003, a negative increase of SLHF covered the epicenter which disappeared two days after the shock. This agrees with to the situation of the Zhongba earthquake.

3.5 Yutian $M_{\mathrm{S}} 7.2$ earthquake on March 21, 2008

On March 21, 2008, a $M_{\mathrm{S}} 7.2$ earthquake occurred in Yutian region, Xinjiang. The earthquake is just located in the connecting zone of the Indian and Eurasian plates. Altun fault and west Kunlun fault are two major faults in the earthquake region. The aftershocks distributed mainly along the fault lines with largest magnitude of $M_{\mathrm{S}}$ 5.2. Figure 9 shows a relatively early appearance of the anomaly on February 21, 2008, just one month before the earthquake. From Figure 10 it can be seen that the anomaly started to spread to the northeast of the epicenter 

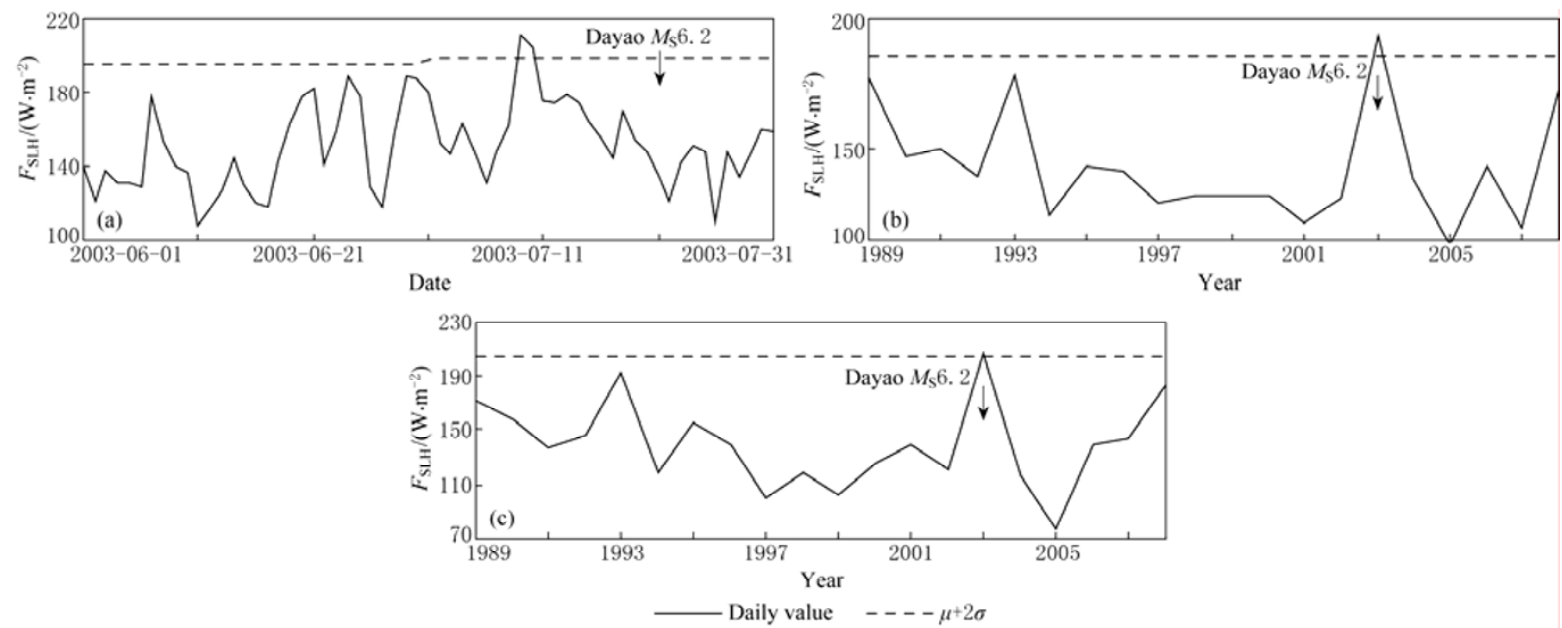

Figure 7 (a) Variations of SLHF $F_{\mathrm{SLH}}$ in the pixel $\left(25.7139^{\circ} \mathrm{N}, 101.25^{\circ} \mathrm{E}\right) 32 \mathrm{~km}$ away from the epicenter of the Dayao $M_{\mathrm{S}} 6.2$ earthquake from June 1 to July 31, 2003; (b) The SLHF $F_{\mathrm{SLH}}$ on 9 July during 1989-2008; (c) The SLHF $F_{\text {SLH }}$ on 10 July during the time interval 1989-2008. Dashed lines indicate the seismic moment.
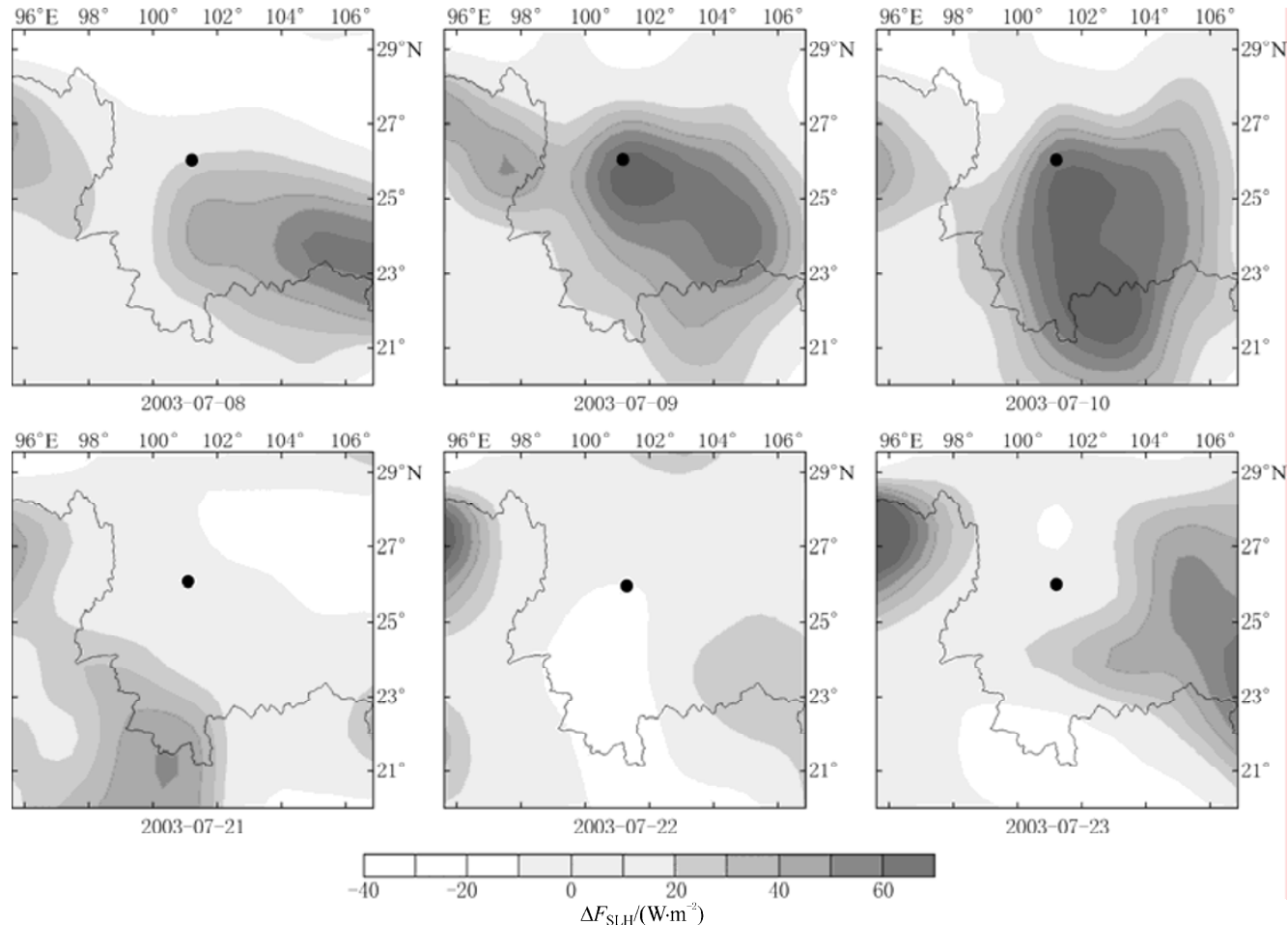

Figure 8 Spatial distribution of SLHF increment $\Delta F_{\text {SLH }}$ in Dayao region before the $M_{\mathrm{S}} 6.2$ earthquake. Dot indicates the epicenter of the Dayao earthquake.

on February 18, forming a large area on February 19 and 20. On February 21, the anomalous regions are distributed along the Altun fault and west Kunlun fault.

\section{Discussion and conclusions}

The cause of surface latent heat flux (SLHF) anomalies before inland earthquakes is not completely under- stood. Pulinets et al $(2006 \mathrm{a}, \mathrm{b})$ considered that the ionization of the near surface air by radon and its progeny products might trigger an interaction between the lithosphere-hydrosphere and atmosphere, which is related to the changes of the near surface electrical field and gas composition. This mechanism comes to a developed model of seismo-ionospheric coupling (Pulinets and 

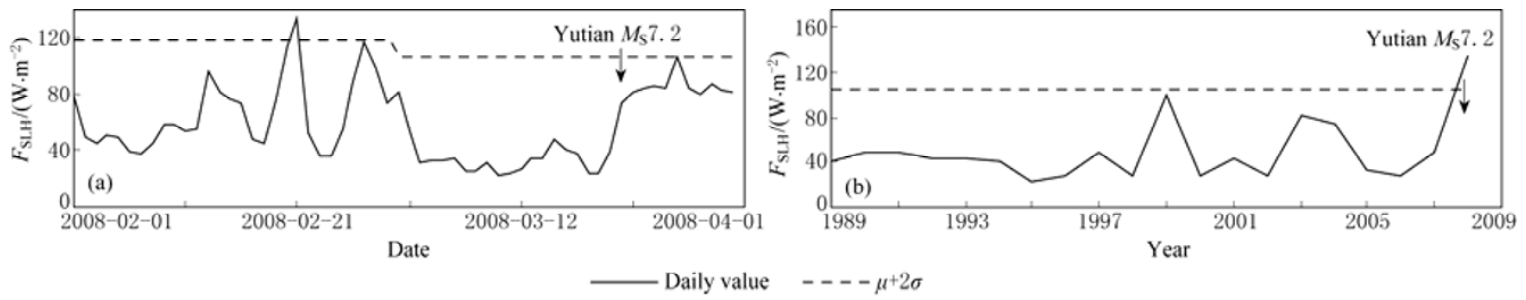

Figure 9 (a) Variations of SLHF $F_{\mathrm{SLH}}$ in the pixel $\left(35.2375^{\circ} \mathrm{N}, 80.625^{\circ} \mathrm{E}\right) 76 \mathrm{~km}$ away from the epicenter of the Yutian $M_{\mathrm{S}} 7.2$ earthquake from February 1, 2008 to March 31, 2008; (b) The SLHF $F_{\mathrm{SLH}}$ on 21 February during the interval 1989-2008. Dashed lines indicate the seismic moment.

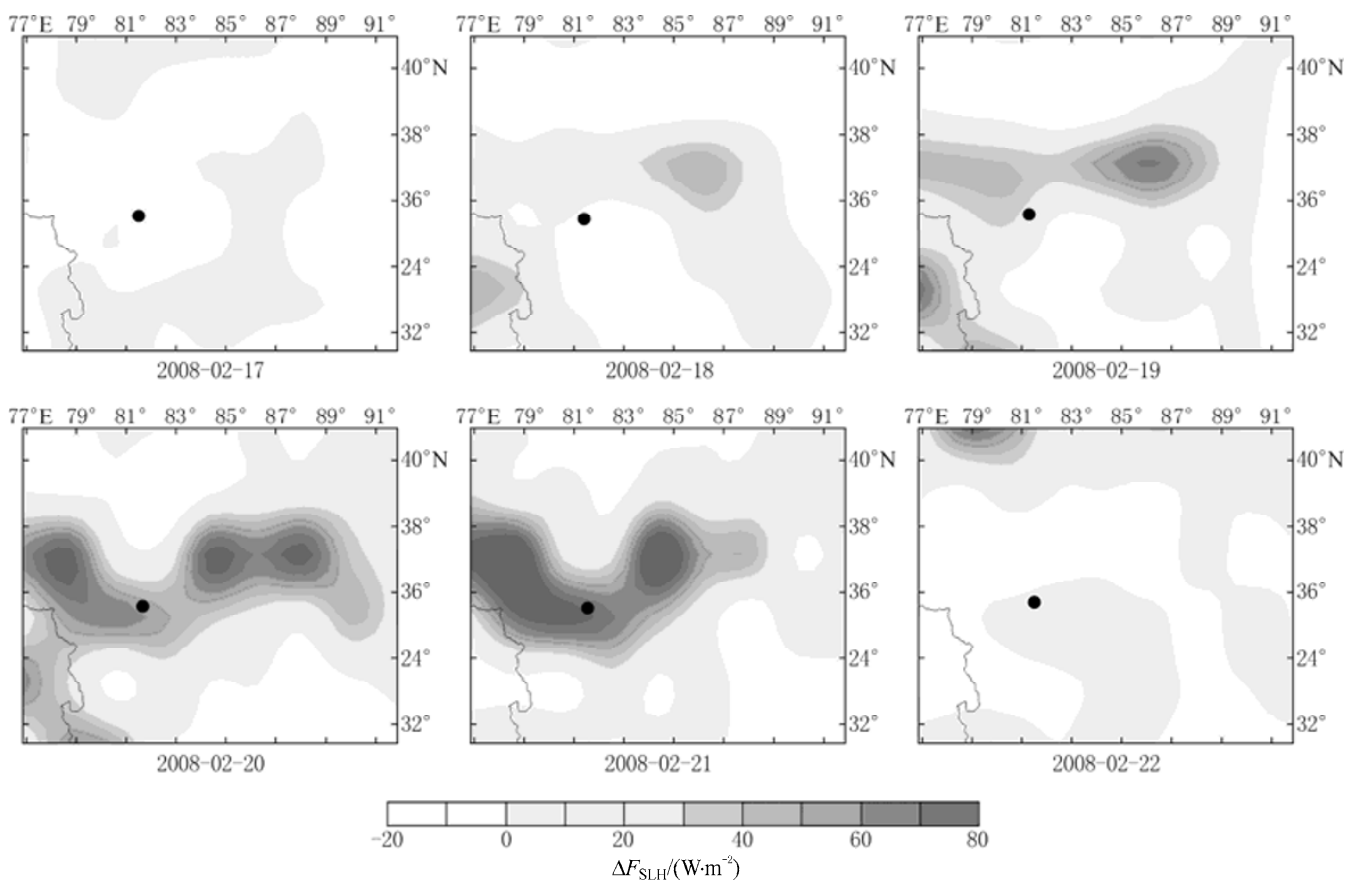

Figure 10 Spatial distribution of SLHF increment $\Delta F_{\mathrm{SLH}}$ in Yutian region before the $M_{\mathrm{S}} 7.2$ earthquake. Dot indicates the epicenter of the Yutian earthquake.

Boyarchuk, 2004). Part of the model describes the generation of anomalous electric field in the zones of earthquake preparation, and involves the process of the formation of gaseous aerosols with water molecules attachment, which is essentially connected with the latent heat variations. A large amount of heat $(3.3-3.8 \mathrm{MJ} / \mathrm{kg})$ is released or consumed during the process, which is the SLHF rise what we observed before the five inland earthquakes in China. It should be pointed out that enough water is necessary in the emergence of obvious SLHF anomaly. The five earthquakes in this paper occurred in lake area (Zhongba, Gaize), moist area (Pu'er, Dayao) and arid area (Yutian), respectively (Table 1). Although there is not so much surface water in arid area as in lake area and moist area, the abundant groundwater and numerous glaciers in Yutian region might provide the necessary condition for the change of SLHF. Every earthquake has its individual properties including the tectonic settings and atmospheric conditions, as well as the concentration of water area or groundwater prevailing in the earthquake epicenters and its surrounding regions. This is why the anomalous SLHFs exhibit different characteristics both in time and space.

On the basis of SLHF variations for five earthquakes, the paper came to the following preliminary conclusions.

1) The time-series of SLHF over the epicenter show the temporal evolution of the anomalies before the shocks: 19 days for Zhongba $M_{\mathrm{S}} 6.0$ earthquake, eight days for Gaize $M_{\mathrm{S}} 6.9$ earthquake, ten days for Pu'er $M_{\mathrm{S}} 6.4$ earthquake, 11-12 days for Dayao $M_{\mathrm{S}} 6.2$ earthquake, and 30 days for Yutian $M_{\mathrm{S}} 7.2$ earthquake. For all 
of the cases, significant anomalies appeared a few weeks before the shock, and it got much weaker when the shock approached (Figures 1a, 3a, 5a, 7a, and 9a).

2) Spatial distribution of SLHF increment shows the anomalous area just covering the epicenters as for the Zhongba (Figure 2) and Dayao earthquake (Figure 8). Because of atmospheric origin and different local conditions, the SLHF anomaly also covered large regions adjacent the epicenter and was not necessarily collocated with the epicenter (Figures 4, 6 and 10). Strong SLHF increment anomalies respectively appeared in the south and north for Gaize (Figure 4) and Pu'er shocks (Figure 6). The distribution of SLHF increment anomalies along the fault lines in Yutian (Figure 10) was probably connected with the local geological structures.

3) The increase of SLHF was tightly related to the season which the earthquake occurs in. As for the five cases, the maximal and minimal anomaly was in summer $\left(125 \mathrm{~W} / \mathrm{m}^{2}\right.$, Pu'er earthquake $)$ and winter $\left(25 \mathrm{~W} / \mathrm{m}^{2}\right.$, Gaize earthquake), respectively.

4) The anomalous SLHF behaviors do exist before the inland earthquakes. To further confirm the reliability of SLHF anomaly, it is necessary to explore its physical mechanism in depth by more earthquake cases.

Acknowledgements Thanks are given to the $\mathrm{Na}$ tional Center for Environmental Prediction (NCEP) for providing the surface latent heat flux.

\section{References}

Chen M H, Deng Z H and Yang Z Z (2006). Surface latent heat flux anomalies prior to the Indonesia $M_{\mathrm{W}} 9.0$ earthquake of 2004. Chinese Science Bulletin 51(1): 118-120.

Chen M H, Deng, Z H, Wang Y, Liao Z H and Zu J H (2007). Primary study on the variation of surface thermal flux before and after the $M_{\mathrm{S}} 5.7$ earthquake of 2005 in Jiujiang, Jiangxi. Seismology and Geology 29(3): 617-626 (in
Chinese with English abstract).

Cervone G, Kafatos M, Napoletani D and Singh R P (2004). Wavelet maxima curves associated with two recent great earthquakes. Nat Hazards Earth Sys 4: 359-374.

Dey S and Singh R P (2003). Surface latent heat flux as an earthquake precursor. Nat Hazards Earth Sys 3: 749-755.

Kalnay E, Kanamitsu M and Kistler R (1996). The NCEP/NCAR 40-year reanalysis project. B Am Meteorol Soc 77(3): 437-471.

Li J P, Wu L X, Wen Z Y and Liu S J (2008). Studies on abnormal surface latent heat flux prior to major coastal and terrestrial earthquakes in China. Science \& Technology Review 26(5): 40-44 (in Chinese with English abstract).

Ouzounov D and Freund F (2004). Mid-infrared emission prior to strong earthquakes analyzed by remote sensing data. Adv Space Res 33: 268-273.

Ouzounov D, Liu D F, Chun K and Taylor P (2007). The outgoing longwave radiation variability prior to the major earthquake by analyzing IR satellite data. Tectonophysics 421: 211-220.

Pulinets S A and Boyarchuk K A (2004). Ionospheric Precursors of Earthquakes. Springer, Berlin, Heidelberg, 315.

Pulinets S A, Ouzounov D and Ciraolo L (2006a). Thermal, atmospheric and ionospheric anomalies around the time of the Colima M7.8 earthquake of 21 January 2003. Ann Geophys 24: 835-849.

Pulinets S A, Ouzounov D, Karelin A V, Boyarchuk K A and Pokhmelnykh L A (2006b). The physical nature of thermal anomalies observed before strong earthquakes. Physics and Chemistry of the Earth 31: 143-153.

Qiang Z J (2001). Satellite-based prediction of earthquakes. EARSel Newsletter 47: $21-26$.

Qiang Z J, Dian C G, Li L, Xu M, Liu T, Zhao Y and Guo M (1999). Satellite thermal infrared brightness temperature anomaly image - shortterm and impending earthquake precursors. Science in China (Series D) 42: 313-324.

Saraf A K and Choudhury S (2005a). NOAA-AVHRR detects thermal anomaly associated with the 26 January 2001 Bhuj earthquake, Gujrat, India. Int J Remote Sens 26: 1 065-1 073.

Saraf A K and Choudhury S (2005b). Satellite detects surface thermal anomalies associated with the Algerian earthquakes of May 2003. Int J Remote Sens 26: 2 705-2 713.

Saraf A K, Rawat V, Banerjee P, Choudhury S, Panda S K, Dasgupta S and Das J D (2008). Satellite detection of earthquake thermal infrared precursors in Iran. Natural Hazards 47(1): 119-135.

Singh R, Simon B and Joshi P C (2001). Estimation of surface latent heat fluxes from IRSP4/MSMR satellite data. Proc Indian Acad Sci (Earth Planet Science) 110(3): 231-238.

Smith S R, Legler D M and Verzone K V (2001). Quantifying uncertainties in NCEP reanalysis using high-quality research vessel observations. $J$ Climate 14: 4 062-4072.

Tronin A A, Hayakawa M and Molchanov O A (2002). Thermal IR satellite data application for earthquake research in Japan and China. J Geodyn 33: 519-534. 